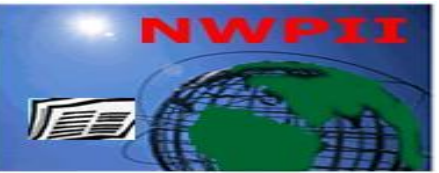

American Journal of Biomedical Sciences

ISSN: 1937-9080

nwpii.com/ajbms

\title{
Recent Advances in Nanoparticles-based Lateral Flow Biosensors
}

\author{
Xuefei Gao ${ }^{1}$, Li-Ping $\mathrm{Xu}^{1}{ }^{*}$, Shu-Feng $\mathrm{Zhou}^{2}$, Guodong Liu ${ }^{3}$, Xueji Zhang ${ }^{1 *}$ \\ ${ }^{1}$ Research Center for Bioengineering and Sensing Technology, University of Science \& Technology Beijing, Beijing, \\ P. R. China \\ ${ }^{2}$ Department of Pharmaceutical Sciences, College of Pharmacy, University of South Florida, FL, USA \\ ${ }^{3}$ Department of Chemistry and Biochemistry, North Dakota State University, Fargo, ND, USA \\ *Corresponding Author \\ Dr Li-Ping Xu \\ Research Center for Bioengineering and Sensing Technology \\ University of Science \& Technology Beijing \\ Beijing, 100083 \\ P. R. China \\ Tel.: +86 10-8237-6831 \\ E-mail: xuliping@ustb.edu.cn \\ Dr Xueji Zhang \\ Research Center for Bioengineering and Sensing Technology \\ University of Science \& Technology Beijing \\ Beijing, 100083 \\ P. R. China \\ Tel.: +86 10-8237-6993 \\ E-mail: zhangxueji@ustb.edu.cn
}

Received: 4 March 2014; $\mid$ Revised: 18 March 2014; $\mid$ Accepted: 26 March 2014

\begin{abstract}
Lateral flow biosensors (LFBs) provide advantages in low cost, simplicity, rapidity, stability and portability, thus making LFBs popular in biomedical, agriculture, food and environmental sciences. This article reviews recent advances of LFBs for bioassays, including the investigation of the improvements achieved by signal-amplification strategies, the application of new nanoparticle labels, novel quantitative system and simultaneous detection. We summarized the outstanding performances of LFBs such as high detection sensitivity, specificity, reproducibility and reliability.
\end{abstract}

Keywords: lateral flow biosensor, point-of-care testing, nanoparticles, bioassays

\section{Introduction}

In the last decades, the detecting of biothreat agents, chemical contaminants and biomolecules has attracted much attention and various new methods including real-time polymerase chain reaction (RT-PCR) [1-4], DNA microarrays [5-8], enzyme linked immunosorbent assay (ELISA) [913], HPLC-MS [14-17] and immunosensor 
techniques [18-23] have been employed. These methods offer high accuracy, but often require time-consuming sample pretreatment, technical expertise, sophisticated and expensive instrumentation, which are inappropriate for point-of-care testing and home testing. Lateral flow biosensors (LFBs), as a promising tool for detecting analyte, have recently attracted considerable interest because of their speed, simplicity, sensitivity, specificity, easy handling, and can potentially provide "instantaneous" diagnosis near the patients [24-33]. Originally the LFBs was used in human chorionic gonadotrophin (HCG) immunoassay and called "sol particle immunoassay" (SPIA) [34,35]. Since then, the LFB was widely applied in environmental monitoring, food safety, and clinical diagnosis for visual (qualitative) and quantitative detecting of various biomolecules and chemical contaminants such as infectious agents [36-41], nucleic acids [42,30,43], proteins [44,33], cells [28], veterinary drugs [45-50], toxins [51-56] and pesticides [57,58]. The principle of LFBs is based on a solid-phase chromatographic test strip containing dry reagents those are activated by applying the fluid sample. Antibodies are immobilized on different positions of the LFB to capture target antigens and the colored detector reagents labeled on antibodies give the colored responses on the test zone and control zone on the LFB. The characteristic colored bands enable visual detection of target analyte without instrumentation. For quantitative measurements, the optical intensities of the test zone and control zone could be recorded simultaneously by corresponding instrumentation $[59,60]$.

The aim of this article is to review major advances in recent years in LFB development and to compare the currently evaluated LFB with the traditional LFB. New strategies from these studies were presented and discussed including:

1. investigation of the improvements achieved by signal-amplification strategies;

2. application of new nanoparticle labels;

3. introducing of novel quantitative system;

4. simultaneous detection of multiple analytes.

\section{LFB assay formats and principle}

The LFB are designed to test the absence or presence of target analyte. The analyte might be the pathogens, hormones, drugs or metabolites. A specific labeled-antigen or labeled-antibody to the analyte is used for recognition. The LFB consists of four sections: sample application pad, conjugate pad, membrane and absorption pad. All of the components are laminated on a common sheet of plastic adhesive backing orderly using the clamshell laminator. Each pad overlaps $2 \mathrm{~mm}$ to allow the migration of sample solution along the LFB during the analysis.

Various possible formats have been described for LFBs, which are depending on the types of target analytes. The competitive assay and sandwich assay are the two most frequently used formats. When the target analyte is with low molecular weight or presenting single specific antigen, it is suitable for employing competitive format $[61,62,48]$. There are two approached based on the competitive format: 1) the specific antibody is firstly dispensed on the test zone. After applying the sample solution (containing the target antigen and the labeled antigen) to the sample application pad, the target antigen and labeled antigen would compete for binding on the specific antibody, which is immobilized on the test zone; 2) the sample solution containing target antigen is firstly incubated with the specific antibody to form the antigen-antibody complex. The antigen-antibody complex and labeled antibody would compete for binding on the specific antigen-protein conjugate, which is immobilized on the test zone [63].

As shown in Figure 1, in a typical competitive format, a monoclonal antibody (specific to target analyte-progesterone) immobilized on the test zone of a nitrocellulose (NC) membrane captures a colored reagent labeled analyte conjugate (progesteroneovalbumin/GNPs conjugate), enabling colored reagent (colloidal gold nanoparticles (GNPs)) to accumulate on the test zone and form a characteristic red line on the test zone. The control line was immobilized by another specific protein to capture the excess colored reagent labeled conjugate. In the present (or higher than 
the cutoff value) of the target analyte, the target analyte (progesterone) and colored reagent labeled analyte (progesterone-ovalbumin/GNPs conjugate) would compete for binding on the test zone. Owing to the binding affinity and steric effect, the target analyte would bind on the test zone prior to colored reagent labeled analyte. In this case, only one characteristic red band can be observed from the control zone. Conversely, in the absence (or lower than the cutoff value) of target analyte, numerous colored reagent-labeled analyte would bind on test zone, and two characteristic red lines can be observed from the test zone and control zone respectively.

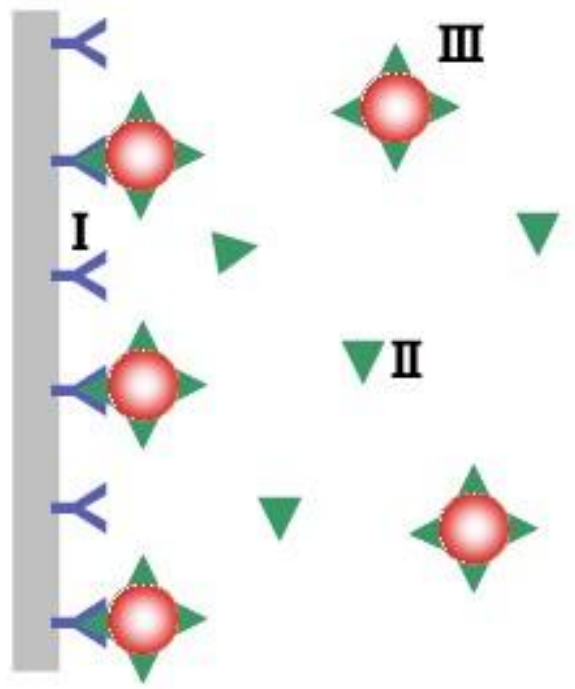

Figure 1. The principle of the competitive thin-layer immuno-affinity chromatography: I ) monoclonal antibody to progesterone immobilized to membrane; II ) progesterone; III ) colloidal gold labeled progesterone-ovalbumin conjugate; IV ,nitrocellulose membrane strip.

On the other hand, when the target analyte owns more than one specific antibodies or DNA aptamers, sandwich format could be employed to test the target analyte [64-70,33,71]. Figure 2 presents the typical DNA aptamers-based sandwich format. A pair of specific DNA aptamers (two aptamer probes, which could bind target thrombin in two different sites) was employed to test target analyte (thrombin). During the detection process, a colored reagent labeled DNA aptamer (GNPs-aptamer 1) was placed on the conjugate pad (a glass-fiber membrane) to serve as the detection reagent; another DNA aptamer (aptamer 2) was immobilized on the test zone to serve as the capture reagent. On the control zone, an additional DNA probe (complementary with the detection aptamer 1) could be used to produce a control signal. When a sample solution was applied on the sample application pad, it would migrate up by capillary action and rehydrate the colored reagent labeled DNA aptamer (GNPsaptamer 1) conjugates on the conjugate pad. Then the binding between the colored reagent labeled DNA aptamer (GNPs-aptamer 1) and target analyte (thrombin) occurred. Subsequently, the mixture passed through the test zone and the bounded target analyte was captured by capture reagent (aptamer 2). The response from the test zone is in proportion to the concentration of the target analyte. The schematic illustration is depicted in Fig. 2B.

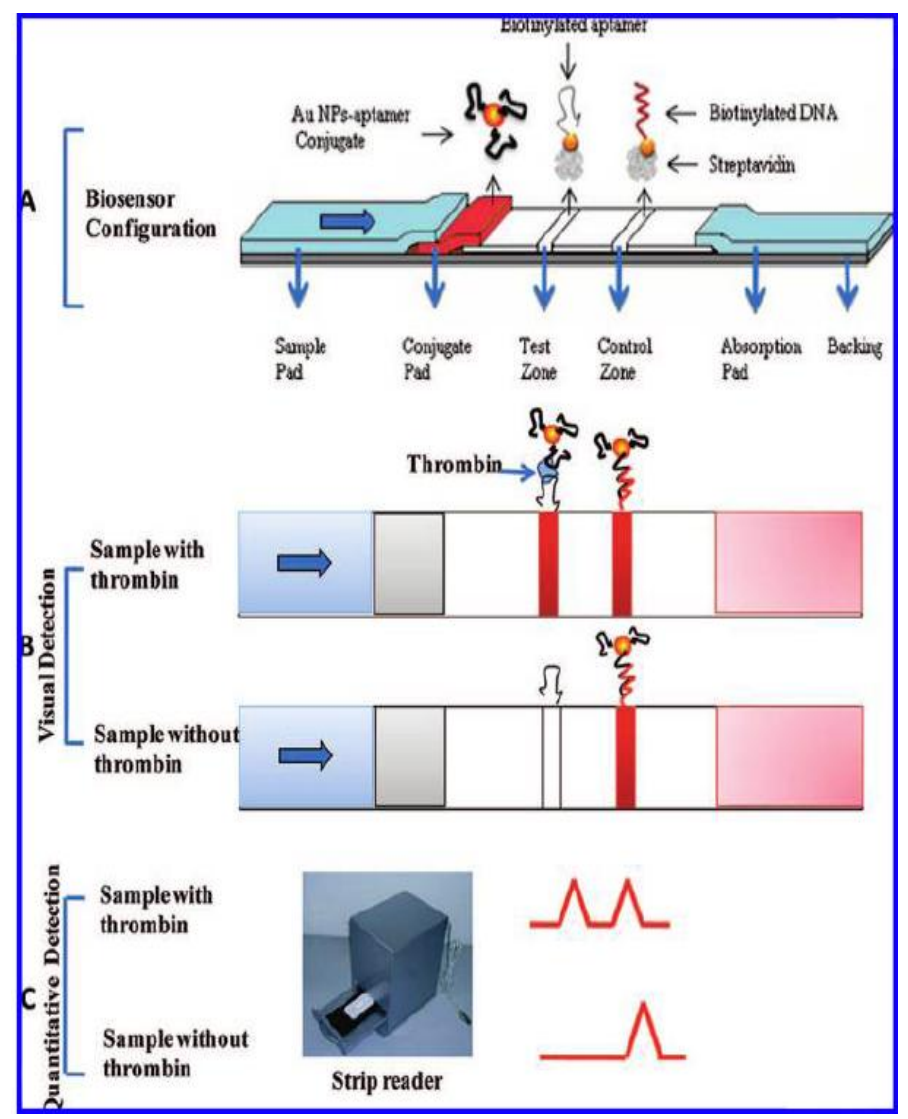

Figure 2. The sandwich format based LFB for thrombin detection [33]. 
To date, this LFB based technology has reached many fields of research such as medicine, agriculture, food and environmental safety. Recently, several review papers describing LFB $[63,72,41,73,74]$, including the paper reported by Posthuma-Trumpie et al. [73] for detection of infectious agents and chemical contaminants and the paper reported by Babacar Ngom et al. [41] for the strengths, weaknesses, opportunities and threats of the LFB. Herein, we aimed to present recent advances of LFBs for biomedical detections, including the investigation of the improvements achieved by signal-amplification strategies, the application of new nanoparticle labels, novel quantitative system and the simultaneous detection.

\section{Signal-amplification strategies}

Colored detector reagents in LFBs such as colloidal god nanoparticle (GNPs), latex, europium, chelate-loaded silica, fluorescent immunoliposomes, green microparticle, etc. are used as labels of antibody or aptamer to detect the presence of target analyte. Among the colored particles, GNPs have been extensively employed due to their inherent advantages, such as intense optical properties, vivid color, hybridization and melting properties, fine biocompatibility, excellent chemical tailorability, distance and aggregate size-dependent optical properties. Thus, antibody or aptamer-GNPs have been used to develop LFBs for a wide variety of analytes. Due to low abundance of targets, high sensitivity is highly desired for LFBs. An effective way for improving the sensitivity of the GNPs-based bioassay is to amplify the Au signal by adopting silver enhancement technology to the traditional bioassay [75-81]. Under the action of the reducing agent, silver ions is prone to gather around the GNPs in the form of silver, the color of the test zone is greatly enhanced due to the silver deposition on the GNPs surface. Wang et al. [78] reported a silver enhancement technologybased sandwich immuno-chromatographic assay for detecting abrin-a. In a typical assay, a range of abrin-a concentrations (0, 0.1, 1.0, 10, 100 and $1000 \mathrm{ng} / \mathrm{mL}$ ) were measured. The accumulation of the GNPs on the test zone and control zone enabled the visual detection within $10 \mathrm{~min}$. Then, the $\mathrm{AgNO}_{3}$ pad and reducer pad were orderly covered on the test zone and control zone. Followed by applying $100 \mu \mathrm{L}$ double distilled water to infiltrate the two pads, the enhancement result of the test strips was determined within 10 min. The detection sensitivity was $0.1 \mathrm{ng} / \mathrm{mL}$ and demonstrated to be increased by 100 -fold in comparison with the conventional LFB assay. Furthermore, no significant cross-reactivity can be obtained from the test strip, showed excellent detection specificity.

Another alternative approach for enhancing the detection limit is to introduce enzymes as labels into the development of biosensors and bioassays. Horseradish peroxi-dase (HRP), glucose oxidase and alkaline phosphatase are the most commonly used enzymes in the LFBs bioassays [82-84,68,85-87]. Parolo and coworkers [68] presented a HRP-GNPs duallabeled LFB for the sensitive detection of Human IgG (HIgG). This strategy was combining the unique optical properties of GNPs and enzyme catalytic amplification, which produce darker products depositing on the GNP surface to enhance the visual effect and the response intensities. Three different HRP substrates, including 3,3,5,5-Tetramethylbenzidine (TMB), 3-Amino-9-ethylcarbazole (AEC), 3,3Diaminobenzidinetetrahydrochloride (DAB) were tested on the LFB and the TMB resulted the most suitable for LFB applications. The study comprised two steps as follows: 1) capturing of the HRP-GNPs dual-labeled conjugate on the test zone (insensitive); 2) signal amplification by applying the HRP substrates on the test zone (sensitive). After signal amplification, the LFB gained sensitivity (up to 1 order of magnitude) without losing the simplicity and the detection reproducibility.

Recently, new advances have been made to develop ultrasensitive analyte (DNA) tests by introducing the signal amplification strategyisothermal strand-displacement polymerase reactions (ISDPR) into the LFB bioassay. ISDPR have been developed to overcome the disadvantages of PCR. No thermal cycling is required in the ISDPR, offering distinct advantages with regard to the cost and simplicity 
of instrumentation. Moreover, ISDPR permits $10^{10}$-fold amplification of a DNA target sequence within $15 \mathrm{~min}$, and the amplified DNA can be used and detected directly without any further purification [88,89]. A LFB combined with isothermal strand-displacement technology was proposed by Lie and co-workers for the detection of human genomic DNA in the aqoeous solutions. The ISDPR solution consisted of a biotin modified hairpin DNA probe, a strand displacement primer, target DNA probe, Klenow polymerase exo-, dNTPs and buffer solution[90]. A 41-mer DNA hairpin probe (containing the target DNA binding site; probe 1) is first immobilized on the surface of GNPs. In the present of the target DNA, it would bind on the specific binding site on the hairpin probe, and then open the hairpin probe forming the duplexes on the surface of GNPs. After introducing the primer and the tag (probe 2 and probe 3 ), the recognition and hybridization with probe 1 occurred. At the same time, probe 1 was undergoing a conformational change and leading to stem separation. In the presence of Klenow polymerase exo-, probe 2 would anneal with the open stem and trigger an extension reaction. During the extension reaction, the target DNA was displaced, which triggered a new round of polymerization reaction. As a result, numerous sequence tagged-duplex DNA complexes were produced throughout this repeating process. In a typical assay, the resulting complexes would be captured on the test zone of the test strip through the binding affinity between the biotin (labeled on the probe 1) and the streptavidin (SA) (immobilized on the test zone). The detection limit of the modified LFS was $0.01 \mathrm{fM}$ of target DNA, which was 1000 times better than published traditional LFS methods. He et al. [91] also reported an ISDPR based LFB for visual detection of R156H-mutant DNA. The detection limit was 1-fM R156H-mutant DNA within 75 min without instrumentation. The specificity was further demonstrated by showing no crossreactivity to distinguish of $\mathrm{R} 156 \mathrm{H}$ - and $\mathrm{R} 156 \mathrm{C}$ mutant DNA on the R156 mutation site through the immobilizing of fluorescein- and biotinmodified hairpin probes in the ISDPR process. And the resulting specificity of the assay was
$100 \%$.

An interesting attempt was carried out recently by Choi and co-workers [92] upon the applying the traditional sandwich format-based LFB with the 2nd conjugate by immobilizing GNPs with different size on the different antibody, and the antibody was designed to bind specifically with the 1 st GNP conjugate. In a typical assay, after the 1st GNPs conjugate was captured on the LFB, the 2nd GNP conjugate would bind on the 1st GNPs to amplify the optical signal by depositing more GNPs on the test zone. In this study, the 1st conjugate was an anti-troponin I antibody immobilized on the 10$\mathrm{nm}$ GNPs blocking with bovine serum albumin (BSA), and the 2nd conjugate was an anti-BSA antibody immobilized on the 40-nm GNPs blocking with human serum albumin. The detection limit of this dual GNP conjugates-based LFB was as low as $0.01 \mathrm{ng} / \mathrm{mL}$ troponin I within $10 \mathrm{~min}$, whereas $1 \mathrm{ng} / \mathrm{mL}$ was detectable by the conventional LFB method, offering a 100-fold signal amplification method than the conventional LFB.

\section{Applications of new nanoparticle labels}

The visible color from the test zone and control zone is generated from the integration and accumulation of the colored detector reagents. Therefore, for successful development of LFB with sufficient sensitivity, the type of colored detector reagents is very important. As mentioned above, the GNPs are the most widely used colored reagent, owing to its notable advantages. However, GNPs still suffer from some drawbacks: the sensitivity is insufficient for low abundance of targets; the signal amplification process could be costly. Therefore, it is significant to finding the suitable and new detector reagents for sensitive detection.

Magnetic nanoparticles and microparticles are attractive as nanomaterials because of their embedded magnetic entities, larger surface-tovolume ratio and they can be magnetically manipulated by using permanent magnets or electromagnets. By considering these advantages, Tang and co-workers [93] synthetised the magnetic nano-gold microspheres (MnGMs; with 
nano- $\mathrm{Fe}_{2} \mathrm{O}_{3}$ particles as core and GNPs as shell) as the colored reagent and employed them for detecting aflatoxin B2 (AFB2) in food samples. The synthesis of the MnGMs comprised six steps: 1) the synthesis of the $\mathrm{SDS}-\mathrm{Fe}_{2} \mathrm{O}_{3}$ complex; 2) immobilizing chitosan on the surface of $\mathrm{Fe}_{2} \mathrm{O}_{3}$ nanoparticles; 3) the synthesis of the chitosan $/ \mathrm{Fe}_{2} \mathrm{O}_{3}$ nanocomposites; 4) cross-linking glutaraldehyde with chitosan, 5) assembling GNPs on the surface of the formed nanocomposites, 6) obtaining MnGMs by magnetic separation. In this typical competitive immuno-reaction, the test zone and control zone were immobilized with BSA-AFB2 and antimouse IgG, respectively. In the absence of target AFB2 (or lower than the cutoff value), two red lines can be observed from both of the test zone and control zone. In the presence of target AFB2, only one red line can be observed from the control zone. The detection limit of the LFB was as low as $0.9 \mathrm{ng} / \mathrm{ml}$ AFB2 without instrument, which was threefold lower compared to a conventional LFB test using gold nanoparticles as colored detector reagents. Moreover, results of the parallel analysis of AFB2 in blank peanut samples and in naturally contaminated samples showed good agreement rate between HPLC method and the LFIBA. Another gold magnetic nanoparticles (GMNs) based LFB was developed for treponema pallidum antibodies (Tp) detection [94]. In this study, a PAA (poly (acrylic acid))coated GMNs (PGMNs) was prepared with recombinant Treponema pallidum antigens ( $\mathrm{r}-\mathrm{Tp}$ ) as the detection reagent. The preparation of detection reagent included the preparation of the pure core/shell of $\mathrm{Fe}_{3} \mathrm{O}_{4} / \mathrm{GNPs}$, coating PAA on the surface of GMNs and immobilizing the targeted moieties on the PGMNs. The purpose of coating PAA on the surface of GMNs is that PGMNs are more stable and monodispersed than GMNs. The PGMNs were further investigated and characterized by fourier transform-infrared spectroscopy (FT-IR), transmission electron microscopy, UV-visible scanning spectrophotometry, thermogravimetric analysis, and Zetasizer methodologies. The detection limit of this method was as low as 1 national clinical unit $/ \mathrm{mL}$ (NCU/mL). The specificity of the PGMNs-based LFIA strips were determined by testing 1020 sera samples from three independent hospitals, exhibiting high values of the specificity for all clinical tests $(>97 \%)$.

An immuno-nanoparticle composed of a silver core and a gold shell (Ag/Au) was synthesized by Liao et al. [95] and applied for the fast screening of aflatoxin $\mathrm{B}_{1}\left(\mathrm{AFB}_{1}\right)$ in food samples. The synthesis of the core-shell $\mathrm{Ag} / \mathrm{Au}$ nanocomposites comprised four steps: 1) The synthesis of $\mathrm{Ag}$ NPs; 2) the reduction of $\mathrm{HAuCl}_{4}$ by introducing $\mathrm{NaBH}_{4}$ solution; 3) the coverage of the $\mathrm{Au}^{0}$ on the surface of $\mathrm{Ag}$ surface. In this study, the $\mathrm{Ag} / \mathrm{Au}$ nanocomparticle was immobilized with monoclonal anti-AFB 1 primary antibodies, and the resulting conjugates were used as detection reagent in the lateral flow strip test. The detection limit (cutoff value) of the $\mathrm{AFB}_{1}$ was observed at $0.1 \mathrm{ng} / \mathrm{mL}$ within $15 \mathrm{~min}$. High sensitivity was also achieved when a blue dye doped latex beads were used as the colored reagent in the LFB for sensitive DNA detection in aqueous solutions and plasma [96]. The strategy was based on the sandwich format using the target DNA and a pair of DNA probes (capture probe and detection probe). The blue dye doped latex beads was immobilized on the detection probe as the detection reagent, and the capture probe was immobilized on the test zone as the capture reagent. The detection limit was $0.1 \mathrm{nM}$ in aqueous solutions and $3.75 \mathrm{fmol}$ in 50 $\mu \mathrm{L}$ of human plasma.

A carbon nanoparticle based competitive LFB was reported by Sua' rez-Pantaleo' $n$ and coworkers [97] for the detection synthetic phytoregulator forchlorfenuron (CPPU). The detection limit of the carbon nanoparticle based LFB was $89 \mathrm{ng} / \mathrm{L}$, and the results of the parallel analysis of fruit samples with incurred residues showed good agreement rate of two reference methods (ELISA and HPLC).

In addition, the use of fluorescent technique [98-105], up-converting phosphorus $[106,107,59,74]$ and technology also allowed an increase in sensitivity and simplicity compared with that for visual detection of traditional colored labels. 


\section{New quantitative system}

Quantity system is significant for the target analysis, because suitable quantity system can avoid the loss of signal which should also mean a consequent increase of assay sensitivity. Recently, Qin and co-workers [108] introduced the concept of thermal contrast into the LFB based bioassay to improve detection sensitivity. After addition of the targets, the captured GNP-antibody-antigen complex on the test zone enabled the visual detection of the target antigen. At low concentrations of antigen, less GNPs was captured on the test zone, resulting in insufficient bound GNPs for visual detection. A laser or lightemitting diode (LED) and an infrared temperature gun were used to irradiate the GNPs on the test zone and control zone. The thermal contrast can extend the analytical sensitivity of the LFB by 32-fold. They further modification of the assay by combination of higher-absorbing nanoparticles and low-absorbing LFB backing materials. As a result, a 1000-fold improvement in sensitivity was obtained. The use of thermal contrast is a promising novel detection strategy for signal amplification of the LFB bioassay.

Li et al. [109] also introduced a high power LED (520-540 nm) into the LFB for detection of clenbuterol (CLE) in swine urine. The LED (520$540 \mathrm{~nm}$ ) was used as light emitter to irradiate the captured GNPs. The reflective optical signal from GNPs was filter and converted to photoelectrical signals. Because GNPs have an affinity for the absorbance in the green region, therefore, the more GNPs were capture on the test strip, the less photoelectrical responses can be obtained. The detection limit of the CLE by the new quantitative system based LFB was $220 \mathrm{pg} / \mathrm{mL}$.

\section{Simultaneous detection}

Recently, research in the laboratory was focused on developing new LFBs for simultaneous detection [110-113]. Compared with the single detection, simultaneous detection offers many advantages such as simple, timesaving, sample saving, and no need for checking the suspected parameters [114,115,71]. A combination of colloidal gold nanoparticles and oligonucleotide LFB was described by Yuichi Oku et al. [116] for the simultaneous detection of antigens (HBs antigen) and antibodies (Treponema pallidum, TP) in specimens. The assay was based on sandwich format. Four labeled antigens were used in the study: GNPs-labeled anti-antigen A, oligonucleotide 1-labeled anti-antigen A, GNPslabeled antigen $\mathrm{B}$ and oligonucleotide 1-labeled antigen B were firstly applied on the application pad. After introducing the sample solution (containing antigen $\mathrm{A}$ and antibody $\mathrm{B}$ ) onto the sample application pad, specific bindings including antigen $\mathrm{A}$ /anti-antigen $\mathrm{A}$ and antibody B/ antigen B occurred. At the same time, two sandwich typed complexes: oligonucleotide 1/antigen A/GNPs and oligonucleotide 1/antibody B/GNPs were formed on the LFB. Subsequently, the solution containing two complexes continued to migrate along the strip. When they reached the two test zone, the two complexes were captured by the complementary oligonucleotide 1 and the complementary oligonucleotide 2 via the DNA-DNA interaction, respectively. Therefore, in the presence of the two target analytes in a specimen, two characteristic red bands can be observed from the two test zones. In contrary, in the absence of target analyte, no red band can be observed. As a result, more than two types of reactions can be detected on a single assay device. The detection limit was $1 / 8 \mathrm{mg} / \mathrm{ml}$ for the TP sensing and 5 $\mathrm{ng} / \mathrm{ml}$ for the HBs sensing.

Zhu et al. [115] detected cardiac troponin I (hs-cTnl) and myoglobin simultaneously to exclude acute myocardial infarction (AMI) via GNPs based LFB. In this study, the specimens of cardiac troponin I (hs-cTnl) and myoglobin were collected from 173 patients with AMI symptoms. The assay was then compared with the commercial LFIA test, and the agreement rates between the two methods were $100 \%$. In the typical assay, two conjugate pads were introduced to the LFB. In the second conjugate pad, monoclonal anti-hs-cTnI detecting antibody (anti-hs-cTnI mAb1) were labeled with GNPs (13 $\mathrm{nm})$, and then coated with biotinylated DNA. Meanwhile, the monoclonal anti-myoglobin detecting antibody (anti-myoglobin mAb1) were 
also labeled with GNPs (13 nm). Another GNPs with size of $41 \mathrm{~nm}$ was coated with streptavidin and then bound with anti-hs-cTnImAb1-labeled GNPs $(13 \mathrm{~nm})$ on the second conjugate pad to block the first conjugate pad as an intensifier. After the modified LFB test for the simultaneous detection of cardiac troponin I (hs-cTnl) and myoglobin, two characteristic red bands can be observed from the two test zones. The sensitivity of the modified LFB and the commercial LFB were $100 \%$ and $80 \%$, respectively, by studying 20 samples, and the both specificities were $100 \%$. A lateral flow strip for simultaneous detection of cyromazine (CA) and melamine (MA) in foods of animal origin was developed by Le et al. [111]. The assay was based on a competitive binding bioassay using GNPs as label. In a typical LFB assay, anti-CA mAbs and GNPs-coated anti-MA mAbs were firstly added on the conjugate pad. The two test zones and control zone were respectively dispensed with CA-BSA, MA-BSA and goat anti-mouse IgG. In the absence of target analyte, the CG-mAb 2.2.4 / 6A11 or CG-mAb 4.1.4 / 5D8 would be captured by the two test zones which were dispensed with CA-BSA and MA-BSA. In the presence of target analyte (concentration more than $25 \mathrm{ng} / \mathrm{ml}$ ), no red band can be observed in the corresponding position. A sensitivities limit at $0.22 \mathrm{ng} / \mathrm{ml}$ and $0.26 \mathrm{ng} / \mathrm{ml}$ were obtained from CA and MA in matrix sample, respectively. The recoveries for $\mathrm{CA}$ and $\mathrm{MA}$ at three concentration levels $(50,100$, and $150 \mathrm{ng} /$ g) were ranged from $73.9 \%$ to $104.2 \%$. Using HPLC as confirmatory method, the validation of the ICA test was achieved by analyzing CA and MA in real samples (muscle, liver of swine, cattle and sheep, and milk). The agreement rates between LFBs and HPLC were $100 \%$.

Kolosova et al. [110] developed a multianalyte lateral-flow technique using GNPslabeled monoclonal antibodies for the simultaneous detection of deoxynivalenol (DON) and zearalenone (ZEA). The sensitivities of the tests were estimated to be $1500 \mu \mathrm{L} / \mathrm{kg}$ and 100 $\mu \mathrm{L} / \mathrm{kg}$ for DON and ZEA, respectively, and the detection time was less than $10 \mathrm{~min}$. Results from these studies have proved the success of test strip applications.

A combination of GNPs based LFB and logic gates ("OR" and "AND" functions) for proteins and small molecules was described by Chen and co-workers [117]. In this study, thrombin and ATP were used as the inputs, split/integrated aptamers were used as the molecular recognition elements, and the GNPs were used as a tracer. After a complete assay, the output signals could be observed from the color change of the test zone. For the "OR" gate detection, in the absence of any inputs $(0,0)$, no color change can be observed from the test zone; in the presence of either $(1,0 ; 0,1)$ or both inputs $(1,1)$, color change can be observed from the test zone. For the "AND" gate detection, in the presence of both inputs $(1,1)$, color change can be observed from the test zone; in the absence of any $(0,0)$ or either inputs $(1,0 ; 0,1)$, no color change can be observed from the test zone. This is the first application of logic gates in LFB detection, opening the new possibility for the analyte analysis in bioassays.

\section{Conclusions and outlook}

This review has summarized the recent progress on LFBs. Major advantages found on LFBs are portable, inexpensive, simple, robust, short assay time (generally several minutes), and do not require complicated equipment and skilled technicians. The unique and remarkable properties of LFBs have paved the way and opened the possibility for the detecting disease biomarkers, infectious agents and biothreat agents in medicine, agriculture, food and environmental safety. The studies described above demonstrate the recent progress of LFB in improving sensitivity including the signalamplification strategies and new nanoparticle labels for achieving lower detection limits. In addition, the LFBs are promising in simultaneous detection of several analytes in contaminated or hazardous samples effectively outside the laboratory. Furthermore, recent breakthroughs in research in the LFB bioassays could also encourage more innovation in the design of novel quantitative system, which would overcome the loss of signal and extend the analytical sensitivity. However, the challenges for current research are 1) "How will the LFB technologies work without 
complicated sample pretreatment?" and 2) "Will it be possible to achieve low volume detection in LFB analysis?" Therefore, future innovative research is expected to lead to advanced LFB by simplicity and practicability improvement, including sample pad pretreatment strategy and introducing with other major technological advances, such as microfluidic technology.

\section{Acknowledgements}

This research was supported by Award Number R21CA137703 from the National Cancer Institute. $\mathrm{X}$. Zhang acknowledges financial support from the Beijing Natural Science Foundation (Grant No. 2122038), the Fundamental Research Funds for the Central Universities and the Chinese 1000 Elites program and USTB start-up fund.

\section{References}

1. Chen C, Ridzon DA, Broomer AJ, Zhou Z, Lee DH, Nguyen JT, Barbisin M, Xu NL, Mahuvakar VR, Andersen MR. Real-time quantification of microRNAs by stem-loop RT-PCR. Nucleic Acids Research 2005; 33 (20):e179-e179. DOI: 10.1093/nar/gni178

2. Pfaffl MW. A new mathematical model for relative quantification in real-time RT-PCR. Nucleic Acids Research 2001; 29 (9):e45e45. DOI: 10.1093/nar/29.9.e45

3. Schmittgen TD, Livak KJ. Analyzing realtime PCR data by the comparative CT method. Nature protocols 2008; 3 (6):11011108. DOI: $10.1038 /$ nprot.2008.73

4. Vandesompele J, De Preter K, Pattyn F, Poppe B, Van Roy N, De Paepe A, Speleman F. Accurate normalization of real-time quantitative RT-PCR data by geometric averaging of multiple internal control genes. Genome biology 2002; 3 (7):research0034.

5. Barad O, Meiri E, Avniel A, Aharonov R, Barzilai A, Bentwich I, Einav U, Gilad S, Hurban P, Karov Y. MicroRNA expression detected by oligonucleotide microarrays: system establishment and expression profiling in human tissues. Genome research 2004; 14 (12):2486-2494. DOI: 10.1101/gr.2845604

6. Kerr MK, Martin M, Churchill GA. Analysis of variance for gene expression microarray data. Journal of computational biology 2000; 7 (6):819-837. DOI: 10.1089/10665270050514954

7. Yang YH, Dudoit S, Luu P, Lin DM, Peng V, Ngai J, Speed TP. Normalization for cDNA microarray data: a robust composite method addressing single and multiple slide systematic variation. Nucleic Acids Research 2002; 30 (4):e15-e15. DOI: 10.1093/nar/30.4.e15

8. Yin JQ, Zhao RC, Morris KV. Profiling microRNA expression with microarrays. Trends in biotechnology 2008; 26 (2):70-76. DOI: 10.1016/j.tibtech.2007.11.007

9. Elshal MF, McCoy JP. Multiplex bead array assays: performance evaluation and comparison of sensitivity to ELISA. Methods 2006; 38 (4):317-323. DOI: 10.1016/j.ymeth.2005.11.010

10. Eteshola E, Leckband D. Development and characterization of an ELISA assay in PDMS microfluidic channels. Sensors and Actuators B: Chemical 2001; 72 (2):129133. DOI: $10.1016 / \mathrm{S} 0925-4005(00) 00640-7$

11. Sblattero D, Berti I, Trevisiol C, Marzari R, Tommasini A, Bradbury A, Fasano A, Ventura A, Not T. Human recombinant tissue transglutaminase ELISA: an innovative diagnostic assay for celiac disease. The American journal of gastroenterology 2000; 95 (5):1253-1257. DOI: 10.1111/j.1572-0241.2000.02018.x

12. Sehr P, Zumbach K, Pawlita M. A generic capture ELISA for recombinant proteins fused to glutathione $<\mathrm{i}>\mathrm{S}</ \mathrm{i}>$-transferase: validation for HPV serology. Journal of immunological methods 2001; 253 (1):153162. DOI: 10.1016/S0022-1759(01)00376-3

13. Vanmechelen E, Vanderstichele $H$, Davidsson P, Van Kerschaver E, Van Der Perre B, Sjögren M, Andreasen N, Blennow K. Quantification of tau phosphorylated at threonine 181 in human cerebrospinal fluid: a sandwich ELISA with a synthetic 
phosphopeptide for standardization. Neuroscience letters 2000; 285 (1):49-52. DOI: 10.1016/S0304-3940(00)01036-3

14. Chandra A, Rana J, Li Y. Separation, identification, quantification, and method validation of anthocyanins in botanical supplement raw materials by HPLC and HPLC-MS. Journal of agricultural and food chemistry 2001; 49 (8):3515-3521. DOI: $10.1021 /$ jf010389p

15. Gika HG, Theodoridis GA, Wingate JE, Wilson ID. Within-day reproducibility of an HPLC-MS-based method for metabonomic analysis: application to human urine. Journal of proteome research 2007; 6 (8):3291-3303. DOI: 10.1021/pr070183p

16. Wilson ID, Plumb R, Granger J, Major H, Williams R, Lenz EM. HPLC-MS-based methods for the study of metabonomics. Journal of Chromatography B 2005; 817 (1):67-76.

DOI: 10.1016/j.jchromb.2004.07.045

17. Ye X, Kuklenyik Z, Needham LL, Calafat AM. Automated on-line column-switching HPLC-MS/MS method with peak focusing for the determination of nine environmental phenols in urine. Analytical Chemistry 2005; 77

(16):5407-5413.

DOI:

10.1021/ac050390d

18. Baxter G, Ferguson J, O'Conno M, Elliott C. Detection of streptomycin residues in whole milk using an optical immunobiosensor. Journal of agricultural and food chemistry 2001; 49 (7):3204-3207. DOI: $10.1021 / \mathrm{jf0014841}$

19. Huang K-J, Niu D-J, Sun J-Y, Zhu X-L, Zhu J-J. Label-free amperometric immunobiosensor based on a gold colloid and Prussian blue nanocomposite film modified carbon ionic liquid electrode. Analytical and bioanalytical chemistry 2010; 397 (8):3553-3561. DOI: 10.1007/s00216010-3868-4

20. Johansson MA, Hellenäs K-E. Matrix effects in immunobiosensor determination of clenbuterol in urine and serum. Analyst 2004; $129 \quad$ (5):438-442. DOI: $10.1039 / \mathrm{b} 316723 b$
21. Johnsson L, Baxter GA, Crooks SR, Brandon DL, Elliott CT. Reduction of sample matrix effects-The analysis of benzimidazole residues in serum by immunobiosensor. Food and agricultural immunology 2002; 14 (3):209-216. DOI: 10.1080/09540100220145000a

22. Marquette CA, Blum LcJ. Regenerable immunobiosensor for the chemiluminescent flow injection analysis of the herbicide 2, 4D. Talanta 2000; 51 (2):395-401. DOI: 10.1016/S0039-9140(99)00298-2

23. Traynor IM, Plumpton L, Fodey TL, Higgins C, Elliott CT. Immunobiosensor detection of domoic acid as a screening test in bivalve molluscs: comparison with liquid chromatography-based analysis. Journal of AOAC International 2006; 89 (3):868-872.

24. Bührer-Sékula S, Smits HL, Gussenhoven GC, Van Leeuwen J, Amador S, Fujiwara T, Klatser PR, Oskam L. Simple and fast lateral flow test for classification of leprosy patients and identification of contacts with high risk of developing leprosy. Journal of Clinical Microbiology 2003; 41 (5):19911995. DOI: 10.1128/JCM.41.5.19911995.2003

25. Delmulle BS, De Saeger SM, Sibanda L, Barna-Vetro I, Van Peteghem $\mathrm{CH}$. Development of an immunoassay-based lateral flow dipstick for the rapid detection of aflatoxin B1 in pig feed. Journal of agricultural and food chemistry 2005; 53 (9):3364-3368. DOI: 10.1021/jf0404804

26. Fenton EM, Mascarenas MR, López GP, Sibbett SS. Multiplex lateral-flow test strips fabricated by two-dimensional shaping. ACS Applied Materials \& Interfaces 2008; 1 (1):124-129. DOI: 10.1021/am800043z

27. He Y, Zhang X, Zeng K, Zhang S, Baloda M, Gurung AS, Liu G. Visual detection of $\mathrm{Hg}<$ sup $>2+</$ sup $>$ in aqueous solution using gold nanoparticles and thymine-rich hairpin DNA probes. Biosensors and Bioelectronics 2011; $26 \quad$ (11):4464-4470. DOI: 10.1016/j.bios.2011.05.003

28. Liu G, Mao X, Phillips JA, Xu H, Tan W, Zeng L. Aptamer- Nanoparticle Strip Biosensor for Sensitive Detection of Cancer 
Cells. Analytical Chemistry 2009; 81 (24):10013-10018. DOI: $10.1021 / \mathrm{ac} 901889 \mathrm{~s}$

29. Liu J, Mazumdar D, Lu Y. A Simple and Sensitive "Dipstick" Test in Serum Based on Lateral Flow Separation of Aptamer Linked Nanostructures. Angewandte Chemie 2006; 118 (47):8123-8127. DOI: 10.1002/ange.200603106

30. Mao X, Ma Y, Zhang A, Zhang L, Zeng L, Liu G. Disposable nucleic acid biosensors based on gold nanoparticle probes and lateral flow strip. Analytical Chemistry 2009; $81 \quad$ (4):1660-1668. $\quad$ DOI: 10.1021/ac8024653

31. Wozniak RA, Waldor MK. Integrative and conjugative elements: mosaic mobile genetic elements enabling dynamic lateral gene flow. Nature Reviews Microbiology 2010; $8 \quad$ (8):552-563. $\quad$ DOI: 10.1038/nrmicro2382

32. Xia X, Xu Y, Zhao X, Li Q. Lateral flow immunoassay using europium chelateloaded silica nanoparticles as labels. Clinical chemistry 2009; 55 (1):179-182. DOI: 10.1373/clinchem.2008.114561

33. Xu H, Mao X, Zeng Q, Wang S, Kawde A-N, Liu G. Aptamer-functionalized gold nanoparticles as probes in a dry-reagent strip biosensor for protein analysis. Analytical Chemistry 2008; 81 (2):669-675. DOI: $10.1021 / \mathrm{ac} 8020592$

34. Leuvering JH. Metal sol particle immunoassay. Google Patents 1982.

35. Leuvering JH, Thal P, Waart Mvd, Schuurs A. Sol particle immunoassay (SPIA). Journal of immunoassay 1980; 1 (1):77-91. DOI: 10.1080/01971528008055777

36. Carter DJ, Cary RB. Lateral flow microarrays: a novel platform for rapid nucleic acid detection based on miniaturized lateral flow chromatography. Nucleic Acids Research 2007; $35 \quad$ (10):e74. DOI: 10.1093/nar/gkm269

37. Cheek BJ, Steel AB, Torres MP, Yu Y-Y, Yang H. Chemiluminescence detection for hybridization assays on the flow-thru chip, a three-dimensional microchannel biochip.
Analytical Chemistry 2001; 73 (24):57775783. DOI: $10.1021 / \mathrm{ac} 0108616$

38. Fisher M, Atiya - Nasagi Y, Simon I, Gordin M, Mechaly A, Yitzhaki S. A combined immunomagnetic separation and lateral flow method for a sensitive on - site detection of Bacillus anthracis sporesassessment in water and dairy products. Letters in applied microbiology 2009; 48 (4):413-418. DOI: $\quad 10.1111 / \mathrm{j} .1472-$ 765X.2008.02542.X

39. Jung BY, Jung SC, Kweon CH. Development of a rapid immunochromatographic strip for detection of Escherichia coli O157. Journal of Food Protection $(2005$; 68 (10):21402143.

40. Nakasone $\mathrm{N}$, Toma $\mathrm{C}, \mathrm{Lu} \mathrm{Y}$, Iwanaga $\mathrm{M}$. Development of a rapid immunochromatographic test to identify enteropathogenic and enterohemorrhagic $<$ i $>$ Escherichia coli $</ \mathrm{i}>$ by detecting EspB. Diagnostic microbiology and infectious disease 2007; 57 (1):21-25. DOI: 10.1016/j.diagmicrobio.2006.05.012

41. Ngom B, Guo Y, Wang X, Bi D. Development and application of lateral flow test strip technology for detection of infectious agents and chemical contaminants: a review. Analytical and bioanalytical chemistry 2010; 397 (3):11131135. DOI: 10.1007/s00216-010-3661-4

42. He Y, Zhang S, Zhang X, Baloda M, Gurung AS, Xu H, Zhang X, Liu G. Ultrasensitive nucleic acid biosensor based on enzymegold nanoparticle dual label and lateral flow strip biosensor. Biosensors and Bioelectronics 2011; 26 (5):2018-2024. DOI: 10.1016/j.bios.2010.08.079

43. Mao X, Xu H, Zeng Q, Zeng L, Liu G. Molecular beacon-functionalized gold nanoparticles as probes in dry-reagent strip biosensor for DNA analysis. Chemical Communications 2009; (21):3065-3067. DOI: $10.1039 / \mathrm{b} 822582 \mathrm{f}$

44. Liu G, Lin Y-Y, Wang J, Wu H, Wai CM, Lin Y. Disposable electrochemical immunosensor diagnosis device based on nanoparticle probe and immunochromatographic strip. Analytical 
Chemistry 2007; 79 (20):7644-7653. DOI: 10.1021/ac070691i

45. Huo T, Peng C, Xu C, Liu L. Immumochromatographic assay for determination of hexoestrol residues. European Food Research and Technology 2007; $225 \quad(5-6): 743-747 . \quad$ DOI: 10.1007/s00217-006-0477-8

46. Liu L, Peng C, Jin Z, Xu C. Development and evaluation of a rapid lateral flow immunochromatographic strip assay for screening 19 - nortestosterone. Biomedical chromatography 2007; 21 (8):861-866. DOI: 10.1002/bmc.832

47. Posthuma-Trumpie GA, Korf J, van Amerongen A. Development of a competitive lateral flow immunoassay for progesterone: influence of coating conjugates and buffer components. Analytical and bioanalytical chemistry 2008; 392 (6):1215-1223. DOI: 10.1007/s00216008-2362-8

48. Qian S, Bau HH. Analysis of lateral flow biodetectors: competitive format. Analytical biochemistry 2004; 326 (2):211-224. DOI: 10.1016/j.ab.2003.12.019

49. Wang X, Li K, Shi D, Xiong N, Jin X, Yi J, Bi D. Development of an immunochromatographic lateral-flow test strip for rapid detection of sulfonamides in eggs and chicken muscles. Journal of agricultural and food chemistry 2007; 55 (6):2072-2078. DOI: 10.1021/jf062523h

50. Zhang G, Wang X, Yang J, Yang Y, Xing G, Li Q, Zhao D, Chai S, Guo J. Development of an immunochromatographic lateral flow test strip for detection of $\beta$-adrenergic agonist clenbuterol residues. Journal of immunological methods 2006; 312 (1):2733. DOI: 10.1016/j.jim.2006.02.017

51. Cha YJ, Kwon SY, Kim TY, Kim JR, Kim HS, Park MH, Park SH, Park AJ, Bai JH, Son HC. Annual Report on External Quality Assessment in Immunoserology in Korea (2009). Journal of Laboratory Medicine and Quality Assurance 2010; 32 (1):45-68.

52. Kawatsu K, Kumeda Y, Taguchi M, Yamazaki-Matsune W, Kanki M, Inoue K. Development and evaluation of immunochromatographic assay for simple and rapid detection of Campylobacter jejuni and Campylobacter coli in human stool specimens. Journal of Clinical Microbiology 2008; 46 (4):1226-1231. DOI: 10.1128/JCM.02170-07

53. Khreich N, Lamourette $\mathrm{P}$, Boutal H, Devilliers $\mathrm{K}$, Créminon $\mathrm{C}$, Volland $\mathrm{H}$. Detection of $<$ i $>\quad$ Staphylococcus $</ i>$ enterotoxin B using fluorescent immunoliposomes as label for immunochromatographic testing. Analytical biochemistry 2008; 377 (2):182-188. DOI: 10.1016/j.ab.2008.02.032

54. Klewitz T, Gessler F, Beer H, Pflanz K, Scheper T. Immunochromatographic assay for determination of botulinum neurotoxin type D. Sensors and Actuators B: Chemical 2006; $113 \quad$ (2):582-589. DOI: 10.1016/j.snb.2005.07.007

55. Lyoo Y, Kleiboeker S, Jang K-Y, Shin N, Kang J-M, Kim C-H, Lee S-J, Sur J-H. A simple and rapid chromatographic strip test for detection of antibody to porcine reproductive and respiratory syndrome virus. Journal of veterinary diagnostic investigation 2005; 17 (5):469-473. DOI: $10.1177 / 104063870501700512$

56. Yan Z, Zhou L, Zhao Y, Wang J, Huang L, Hu K, Liu H, Wang H, Guo Z, Song Y. Rapid quantitative detection of $<\mathrm{i}>$ Yersinia pestis $</ i>$ by lateral-flow immunoassay and up-converting phosphor technology-based biosensor. Sensors and Actuators B: Chemical 2006; 119 (2):656-663. DOI: 10.1016/j.snb.2006.01.029

57. Guo Y-R, Liu S-Y, Gui W-J, Zhu G-N. Gold immunochromatographic assay for simultaneous detection of carbofuran and triazophos in water samples. Analytical biochemistry 2009; 389 (1):32-39. DOI: 10.1016/j.ab.2009.03.020

58. Kranthi K, Davis M, Mayee C, Russell D, Shukla R, Satija U, Kshirsagar M, Shiware D, Kranthi S. Development of a colloidalgold based lateral-flow immunoassay kit for 'quality-control'assessment of pyrethroid and endosulfan formulations in a novel single strip format. Crop protection 2009; 
28 (5):428-434.

DOI:

10.1016/j.cropro.2009.01.003

59. Hampl J, Hall M, Mufti NA, Yao Y-mM, MacQueen DB, Wright WH, Cooper DE. Upconverting phosphor reporters in immunochromatographic assays. Analytical biochemistry 2001; 288 (2):176-187. DOI: 10.1006/abio.2000.4902

60. Takanashi S, Okame M, Shiota T, Takagi M, Yagyu F, Tung PG, Nishimura S, Katsumata N, Igarashi $\mathrm{T}$, Okitsu S. Development of a rapid immunochromatographic test for noroviruses genogroups I and II. Journal of virological methods 2008; 148 (1):1-8. DOI: 10.1016/j.jviromet.2007.10.010

61. Laitinen MP, Vuento M. Immunochromatographic assay for quantitation of milk progesterone. Acta Chemica Scandinavica 1996; 50 (2):141145. DOI: 10.3891/acta.chem.scand.500141

62. O'Keeffe M, Crabbe P, Salden M, Wichers J, Van Peteghem C, Kohen F, Pieraccini G, Moneti G. Preliminary evaluation of a lateral flow immunoassay device for screening urine samples for the presence of sulphamethazine. Journal of immunological methods 2003; 278 (1):117-126. DOI: 10.1016/S0022-1759(03)00207-2

63. Anfossi L, Baggiani C, Giovannoli C, D’Arco G, Giraudi G. Lateral-flow immunoassays for mycotoxins and phycotoxins: a review. Analytical and bioanalytical chemistry 2013; 405 (2-3):467-480. DOI: 10.1007/s00216012-6033-4

64. Bamrungsap S, Apiwat C, Chantima W, Dharakul T, Wiriyachaiporn N. Rapid and sensitive lateral flow immunoassay for influenza antigen using fluorescently-doped silica nanoparticles. Microchimica Acta 2014; $181 \quad(1-2): 223-230 . \quad$ DOI: 10.1007/s00604-013-1106-4

65. Drygin YF, Blintsov AN, Grigorenko VG, Andreeva IP, Osipov AP, Varitzev YA, Uskov AI, Kravchenko DV, Atabekov JG. Highly sensitive field test lateral flow immunodiagnostics of PVX infection. Applied microbiology and biotechnology
2012; $93 \quad(1): 179-189 . \quad$ DOI: 10.1007/s00253-011-3522-X

66. Hou S-Y, Hsiao Y-L, Lin M-S, Yen C-C, Chang C-S. MicroRNA detection using lateral flow nucleic acid strips with gold nanoparticles. Talanta 2012; 99:375-379. DOI: 10.1016/j.talanta.2012.05.067

67. Jin W, Yamada K, Ikami M, Kaji N, Tokeshi M, Atsumi Y, Mizutani M, Murai A, Okamoto A, Namikawa T. Application of IgY to sandwich enzyme-linked immunosorbent assays, lateral flow devices, and immunopillar chips for detecting staphylococcal enterotoxins in milk and dairy products. Journal of microbiological methods 2013; 92 (3):323-331. DOI: 10.1016/j.mimet.2013.01.001

68. Parolo C, de la Escosura-Muñiz A, Merkoçi A. Enhanced lateral flow immunoassay using gold nanoparticles loaded with enzymes. Biosensors and Bioelectronics 2013; $40 \quad$ (1):412-416. DOI: 10.1016/j.bios.2012.06.049

69. Pöhlmann C, Dieser I, Sprinzl M. A lateral flow assay for identification of Escherichia coli by ribosomal RNA hybridisation. Analyst 2014; 139 (5):1063-1071. DOI: $10.1039 / \mathrm{c} 3 \mathrm{an} 02059 \mathrm{~b}$

70. Xiang $\mathrm{T}$, Jiang $\mathrm{Z}$, Zheng J, Lo $\mathrm{C}$, Tsou $\mathrm{H}$, Ren G, Zhang J, Huang A, Lai G. A novel double antibody sandwich-lateral flow immunoassay for the rapid and simple detection of hepatitis $\mathrm{C}$ virus. International journal of molecular medicine 2012; 30 (5):1041.

71. Zhu J, Zou N, Zhu D, Wang J, Jin Q, Zhao J, Mao H. Simultaneous Detection of HighSensitivity Cardiac Troponin I and Myoglobin by Modified Sandwich Lateral Flow Immunoassay: Proof of Principle. Clinical chemistry 2011; 57 (12):1732-1738. DOI: 10.1373/clinchem.2011.171694

72. Karakus C, Salih BA. Comparison of the lateral flow immunoassays (LFIA) for the diagnosis of $<\mathrm{i}>$ Helicobacter pylori $</ \mathrm{i}>$ infection. Journal of immunological methods 2013; 396 (1):8-14. DOI: 10.1016/j.jim.2013.08.010 
73. Posthuma-Trumpie GA, Korf J, van Amerongen A. Lateral flow (immuno) assay: its strengths, weaknesses, opportunities and threats. A literature survey. Analytical and bioanalytical chemistry 2009; 393 (2):569582. DOI: $10.1007 / \mathrm{s} 00216-008-2287-2$

74. Tjon Kon Fat EM, Abrams WR, Niedbala RS, Corstjens PL. Lateral Flow Sandwich Assay Utilizing Upconverting Phosphor (UCP) Reporters. Methods in Cell Biology 2012; 112:203-234. DOI: 10.1016/B978-0-12405914-6.00011-1

75. Anfossi L, Di Nardo F, Giovannoli C, Passini $C$, Baggiani C. Increased sensitivity of lateral flow immunoassay for ochratoxin A through silver enhancement. Analytical and bioanalytical chemistry 2013; 405 (30):9859-9867. DOI: 10.1007/s00216-0137428-6

76. Lai W, Tang D, Que X, Zhuang J, Fu L, Chen G. Enzyme-catalyzed silver deposition on irregular-shaped gold nanoparticles for electrochemical immunoassay of alpha-fetoprotein. Analytica chimica acta 2012; 755:62-68. DOI: 10.1016/j.aca.2012.10.028

77. Liu C-C, Yeung C-Y, Chen P-H, Yeh M-K, Hou S-Y. < i $>$ Salmonella $</ \mathrm{i}>$ detection using $16 \mathrm{~S}$ ribosomal DNA/RNA probe-gold nanoparticles and lateral flow immunoassay. Food chemistry 2013; 141 (3):2526-2532. DOI: 10.1016/j.foodchem.2013.05.089

78. Wang W, Wu W-Y, Zhong X, Miao Q, Zhu JJ. Aptamer-based PDMS-gold nanoparticle composite as a platform for visual detection of biomolecules with silver enhancement. Biosensors and Bioelectronics 2011; 26 (7):3110-3114.

DOI: 10.1016/j.bios.2010.10.034

79. Wang Z, Duan N, Li J, Ye J, Ma S, Le G. Ultrasensitive chemiluminescent immunoassay of Salmonella with silver enhancement of nanogold labels. Luminescence 2011; 26 (2):136-141. DOI: 10.1002/bio.1196

80. Wen J, Zhou S, Yuan Y. Graphene oxide as nanogold carrier for ultrasensitive electrochemical immunoassay of $<$ i $>$ Shewanella oneidensis $\langle/$ i $>$ with silver enhancement strategy. Biosensors and Bioelectronics 2014; 52:44-49. DOI: 10.1016/j.bios.2013.08.022

81. Yang W, Li X-b, Liu G-w, Zhang B-b, Zhang Y, Kong T, Tang J-j, Li D-n, Wang Z. A colloidal gold probe-based silver enhancement immunochromatographic assay for the rapid detection of abrin-a. Biosensors and Bioelectronics 2011; 26 (8):3710-3713. DOI: 10.1016/j.bios.2011.02.016

82. Fung K-K, Chan CP-Y, Renneberg R. Development of enzyme-based bar codestyle lateral-flow assay for hydrogen peroxide determination. Analytica chimica $\begin{array}{llll}\text { acta 2009; } 634 & \text { (1):89-95. DOI: }\end{array}$ 10.1016/j.aca.2008.11.064

83. Kiba Y, Otani Y, Yasukawa T, Mizutani F. Electrochemical detection of redox species flowing in a nitrocellulose membrane and application to quantitative immunochromatography. Electrochimica Acta 2012; 81:14-19. DOI: 10.1016/j.electacta.2012.07.074

84. Lönnberg M, Carlsson J. Quantitative detection in the attomole range for immunochromatographic tests by means of a flatbed scanner. Analytical biochemistry 2001; $293 \quad$ (2):224-231. DOI: 10.1006/abio.2001.5130

85. Tufanálz M. Nanoparticle embedded enzymes for improved lateral flow sensors. Analyst 2013; $138 \quad$ (15):4255-4259. DOI: 10.1039/c3an00733b

86. Yamaguchi M, Matsuda Y, Sasaki S, Sasaki M, Kadoma Y, Imai Y, Niwa D, Shetty V. Immunosensor with fluid control mechanism for salivary cortisol analysis. Biosensors and Bioelectronics 2013; 41:186-191.

DOI: 10.1016/j.bios.2012.08.016

87. Zhang C, Zhang Y, Wang S. Development of multianalyte flow-through and lateral-flow assays using gold particles and horseradish peroxidase as tracers for the rapid determination of carbaryl and endosulfan in agricultural products. Journal of agricultural and food chemistry 2006; 54 (7):2502-2507. DOI: 10.1021/jf0531407 
88. Dong H, Zhang J, Ju H, Lu H, Wang S, Jin S, Hao K, Du H, Zhang X. Highly sensitive multiple microRNA detection based on fluorescence quenching of graphene oxide and isothermal strand-displacement polymerase reaction. Analytical Chemistry 2012; $84 \quad$ (10):4587-4593. DOI: 10.1021/ac300721u

89. He Y, Zeng K, Zhang S, Gurung AS, Baloda M, Zhang X, Liu G. Visual detection of gene mutations based on isothermal stranddisplacement polymerase reaction and lateral flow strip. Biosensors and Bioelectronics 2012; 31 (1):310-315. DOI: 10.1016/j.bios.2011.10.037

90. Lie P, Liu J, Fang Z, Dun B, Zeng L. A lateral flow biosensor for detection of nucleic acids with high sensitivity and selectivity. Chemical Communications 2012; 48 (2):236-238. DOI: 10.1039/c1cc15878c

91. He Y, Zeng K, Zhang X, Gurung AS, Baloda $\mathrm{M}, \mathrm{Xu} \mathrm{H}, \mathrm{Liu} \mathrm{G}$. Ultrasensitive electrochemical detection of nucleic acid based on the isothermal strand-displacement polymerase reaction and enzyme dual amplification. Electrochemistry Communications 2010; 12 (7):985-988. DOI: 10.1016/j.elecom.2010.05.007

92. Choi DH, Lee SK, Oh YK, Bae BW, Lee SD, Kim S, Shin Y-B, Kim M-G. A dual gold nanoparticle conjugate-based lateral flow assay (LFA) method for the analysis of troponin I. Biosensors and Bioelectronics 2010; $25 \quad$ (8):1999-2002. DOI: 10.1016/j.bios.2010.01.019

93. Tang D, Sauceda J, Lin Z, Ott S, Basova E, Goryacheva I, Biselli S, Lin J, Niessner R, Knopp D. Magnetic nanogold microspheres-based lateral-flow immunodipstick for rapid detection of aflatoxin $\mathrm{B}<\mathrm{sub}>2</$ sub $>$ in food. Biosensors and Bioelectronics 2009; 25 (2):514-518.

DOI: 10.1016/j.bios.2009.07.030

94. Yang D, Ma J, Zhang Q, Li N, Yang J, Raju PA, Peng M, Luo Y, Hui W, Chen C. Polyelectrolyte-Coated Gold Magnetic Nanoparticles for Immunoassay Development: Toward Point of Care
Diagnostics for Syphilis Screening. Analytical Chemistry 2013; 85 (14):66886695. DOI: 10.1021/ac400517e

95. Liao J-Y, Li H. Lateral flow immunodipstick for visual detection of aflatoxin B1 in food using immuno-nanoparticles composed of a silver core and a gold shell. Microchimica Acta 2010; 171 (3-4):289-295. DOI: 10.1007/s00604-010-0431-0

96. Mao X, Wang W, Du TE. Dry-reagent nucleic acid biosensor based on blue dye doped latex beads and lateral flow strip. Talanta 2013; 114:248-253. DOI: 10.1016/j.talanta.2013.04.044

97. Suárez-Pantaleón C, Wichers J, AbadSomovilla A, van Amerongen A, AbadFuentes A. Development of an immunochromatographic assay based on carbon nanoparticles for the determination of the phytoregulator forchlorfenuron. Biosensors and Bioelectronics 2013; 42:170-176. DOI: 10.1016/j.bios.2012.11.001

98. Berlina AN, Taranova NA, Zherdev AV, Vengerov YY, Dzantiev BB. Quantum dotbased lateral flow immunoassay for detection of chloramphenicol in milk. Analytical and bioanalytical chemistry 2013; 405 (14):4997-5000. DOI: 10.1007/s00216013-6876-3

99. Chen R, Li H, Zhang H, Zhang S, Shi W, Shen J, Wang Z. Development of a lateral flow fluorescent microsphere immunoassay for the determination of sulfamethazine in milk. Analytical and bioanalytical chemistry 2013; 405 (21):6783-6789. DOI: 10.1007/s00216-013-7150-4

100. Dudek MM, Kent NJ, Gu P, Fan ZH, Killard AJ. Development of a fluorescent method for detecting the onset of coagulation in human plasma on microstructured lateral flow platforms. Analyst 2011; 136 (9):18161825. DOI: 10.1039/c0an00907e

101. Juntunen E, Myyryläinen T, Salminen T, Soukka T, Pettersson K. Performance of fluorescent europium (III) nanoparticles and colloidal gold reporters in lateral flow bioaffinity assay. Analytical biochemistry 
2012; $428 \quad(1): 31-38 . \quad$ DOI: 10.1016/j.ab.2012.06.005

102. Leonardi GP, Wilson AM, Zuretti AR. Comparison of conventional lateral-flow assays and a new fluorescent immunoassay to detect influenza viruses. Journal of virological methods 2013; 189 (2):379-382. DOI: 10.1016/j.jviromet.2013.02.008

103. Li X, Lu D, Sheng Z, Chen K, Guo X, Jin M, Han H. A fast and sensitive immunoassay of avian influenza virus based on label-free quantum dot probe and lateral flow test strip. Talanta 2012; 100:1-6. DOI: 10.1016/j.talanta.2012.08.041

104. Nabatiyan A, Baumann MA, Parpia Z, Kelso D. A lateral flow-based ultra-sensitive p24 HIV assay utilizing fluorescent microparticles. JAIDS Journal of Acquired Immune Deficiency Syndromes 2010; 53 (1):55-61.

DOI: 10.1097/QAI.0b013e3181c4b9d5

105. Wang Y, Nugen SR. Development of fluorescent nanoparticle-labeled lateral flow assay for the detection of nucleic acids. Biomedical microdevices 2013; 15 (5):751758. DOI: 10.1007/s10544-013-9760-1

106. Corstjens P, Zuiderwijk M, Brink A, Li S, Feindt H, Niedbala RS, Tanke H. Use of up-converting phosphor reporters in lateralflow assays to detect specific nucleic acid sequences: a rapid, sensitive DNA test to identify human papillomavirus type 16 infection. Clinical chemistry 2001; 47 (10):1885-1893.

107. Corstjens PL, Zuiderwijk M, Nilsson M, Feindt H, Sam Niedbala R, Tanke HJ. Lateral-flow and up-converting phosphor reporters to detect single-stranded nucleic acids in a sandwich-hybridization assay. Analytical biochemistry 2003; 312 (2):191200. DOI: 10.1016/S0003-2697(02)00505-5

108. Qin Z, Chan WC, Boulware DR, Akkin T, Butler EK, Bischof JC. Significantly improved analytical sensitivity of lateral flow immunoassays by using thermal contrast. Angewandte Chemie 2012; 124 (18):4434-4437.

DOI:

10.1002/ange.201200997
109. Li C, Luo W, Xu H, Zhang Q, Xu H, Aguilar ZP, Lai W, Wei H, Xiong Y. Development of an immunochromatographic assay for rapid and quantitative detection of clenbuterol in swine urine. Food Control 2013; 34 (2):725-732. DOI: 10.1016/j.foodcont.2013.06.021

110. Kolosova AY, De Saeger S, Sibanda L, Verheijen R, Van Peteghem C. Development of a colloidal gold-based lateral-flow immunoassay for the rapid simultaneous detection of zearalenone and deoxynivalenol. Analytical and bioanalytical chemistry 2007; 389 (78):2103-2107. DOI: 10.1007/s00216-007$1642-\mathrm{Z}$

111. Le T, Yan P, Xu J, Hao Y. A novel colloidal gold-based lateral flow immunoassay for rapid simultaneous detection of cyromazine and melamine in foods of animal origin. Food chemistry 2013; 138 (2):1610-1615. DOI: 10.1016/j.foodchem.2012.11.077

112. Renger F, Bang H, Feist E, Fredenhagen G, Natusch A, Backhaus M, Burmester G-R, Egerer K. Research article Immediate determination of ACPA and rheumatoid factor-a novel point of care test for detection of anti-MCV antibodies and rheumatoid factor using a lateral-flow immunoassay. 2010.

113. Taranova NA, Byzova NA, Zaiko VV, Starovoitova TA, Vengerov YY, Zherdev $\mathrm{AV}$, Dzantiev BB. Integration of lateral flow and microarray technologies for multiplex immunoassay: application to the determination of drugs of abuse. Microchimica Acta 2013; 180 12):1165-1172. DOI: $10.1007 / \mathrm{s} 00604-013-$ 1043-2

114. Wang Y-K, Yan Y-X, Ji W-H, Wang H-a, Li S-Q, Zou Q, Sun J-H. Rapid Simultaneous Quantification of Zearalenone and Fumonisin B1 in Corn and Wheat by Lateral Flow Dual Immunoassay. Journal of agricultural and food chemistry 2013; 61 (21):5031-5036. DOI: 10.1021/jf400803q

115. Zhu J, Zou N, Mao H, Wang P, Zhu D, Ji H, Cong $\mathrm{H}$, Sun $\mathrm{C}$, Wang $\mathrm{H}$, Zhang $\mathrm{F}$. 
Evaluation of a modified lateral flow immunoassay for detection of highsensitivity cardiac troponin I andmyoglobin. Biosensors and Bioelectronics 2013; 42:522-525.

DOI:

10.1016/j.bios.2012.10.016

116. Oku Y, Kamiya K, Kamiya H, Shibahara Y, Ii T, Uesaka Y. Development of oligonucleotide lateral-flow immunoassay for multi-parameter detection. Journal of immunological methods 2001; 258 (1):7384. DOI: 10.1016/S0022-1759(01)00470-7
117. Chen J, Fang Z, Lie P, Zeng L. Computational lateral flow biosensor for proteins and small molecules: a new class of strip logic gates. Analytical Chemistry 2012; 84 (15):6321-6325. DOI: $10.1021 / \mathrm{ac} 301508 \mathrm{~b}$ 